\title{
CHARACTERISATION OF RECENT AND FUTURE CLIMATIC TRENDS IN THE REGION OF GUELMIM (MOROCCO)
}

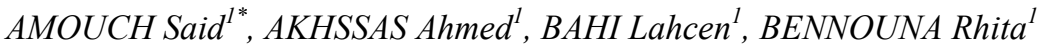 \\ ${ }^{1}$ Laboratory of Applied Geophysics, Engineering, Geotechnical and Environmental Geology, Mohammedia School of \\ Engineers, Rabat
}

\begin{abstract}
According to the Intergovernmental Panel on Climate Change (IPCC), climate change is manifested by the increase in average surface atmospheric temperatures and a decrease in rainfall. The impacts are multiple, complex and differentiated from one region to another in the world. In the Guelmim region (southern Morocco), climate change is manifested by severe droughts and/or recurrent floods. The objective of this study is to characterize the recent and future climate variability in the Guelmim region based on time series of precipitation, the study period goes from 1985 to 2017, and from 2020 to 2099 using Standardized Precipitation Index (SPI).Results of SPI analysis indicate that the most notable droughts for their varying intensity, duration and frequency occurred during the 1992-94 and 1997-2000 periods. Future analysis indicates the study area will face several extended periods of drought and wet during 2020 to 2099. The results of this study show also the link between North Atlantic Oscillation and winter precipitation in Guelmim, which are associated with the negative phase of NAO. The purpose of the study is to have a good management of crops and water resources in Guelmim region and either to insure a sustainable management of environment.
\end{abstract}

Key words: Guelmim; drought; SPI, NAO, Flood.

\section{Introduction}

Some unexpectd impacts of climate change are beginning to become apparent at the regional level everywhere in the world. For example, over the past two centuries, the number of devastating floods is growing faster than other disasters [1]. The fast urbanism development has increased the risk of flooding. The Lack of adequate drainage systems, the construction encroaching on waterways, the reduction of green spaces and an inadequate planning have made many cities vulnerable to flash floods [2].

Morocco is not immune to these considerations. Indeed, recurrent droughts have prevailed for several years, from time to time by sudden and destructive thunderstorms causing devastating floods, which led to an early awareness of the danger posed by climate disturbances. Morocco recorded no less than 35 episodes floods between 1951 and 2015. Flash floods are capable of turning the dry beds of the "Oueds" into violent and destructive torrents [3]. For example, over the past 45 years, the major floods in the Guelmim's region have occurred in 1968, 1985, 2010 and 2014; These floods caused considerable damage [4].

The aim of this study is to characterize the variability of the climate of Guelmim, region which is located in southern Morocco ; and to study the evolution of recent and future climate through precipitation; as well as quantifying aridity by measuring the Standardized Precipitation Index (SPI). The interconnection between this index and the North
Atlantic Oscillation (NAO) is also studied to understand its relation with winter precipitation.

\section{Study area}

\subsection{Geographic location}

Guelmim region is located at $200 \mathrm{~km}$ in the South of Agadir. The study area is the hydrological unit of Guelmim with a global area of about $10.000 \mathrm{Km}^{2}$, it superimposed with the province of Guelmim.

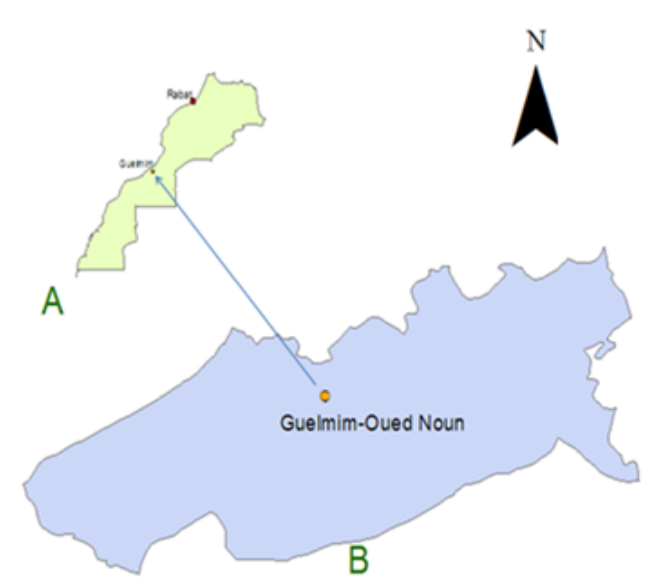

Guelmim's province

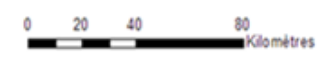

Corresponding author: saidmch@gmail.com 
Fig. 1. Location of the province of Guelmim in Moroccan map.

Guelmim station is located at $\left(29^{\circ} 1^{\prime} \mathrm{N} ; 10^{\circ} 3^{\prime} \mathrm{W}\right)$ with an altitude of $300 \mathrm{~m}$. The climate of Guelmim region is tempered by oceanic influences. Annual rainfall is $135 \mathrm{~mm}$ and the rainy season is limited to a few days where three-quarters of annual precipitation is recorded. The rainy season start from November to March but the dry season is observed for the remainder of the year.

\subsection{The climate hydrology and urbanization of the study area}

The most watered months are, November $(38 \mathrm{~mm})$, December (16mm), January (14mm), February (20mm) and March $(17 \mathrm{~mm})$, and the driest months start from April to October.

The rainfall regime is characterized by a frequent dry periods with some few wet periods. The way the rains are distributed make the difference between the years. The average maximums relative humidity measured at the Guelmim station ranges between 70 and $93 \%$; this is equivalent to dry air or moderately moist air. The average minimum relative humidity measured ranges from 21 to $57 \%$.

The main Oued in the Hydrological Unit of Guelmim are:

1- The Oued Seyyad: it originates at $1200 \mathrm{~m}$ of altitude on the slopes of the Anti-Atlas, and its flow is in the East-West direction for $152 \mathrm{~km}$ and receives many affluents, especially on the right bank, this Oued delimits the Seyyad sub-basin;

2- Oued Bouissafene: it is $82 \mathrm{~km}$ long and its watershed totals $1964 \mathrm{~km} 2$. The river beds are few, this Oued delimits the Bouissaffene sub-basin;

3-Oued Aouiroera, $56 \mathrm{~km}$ in length, drains the sub-basin occupying the North

West of the study area and covering an area of 1036 $\mathrm{km} 2$.

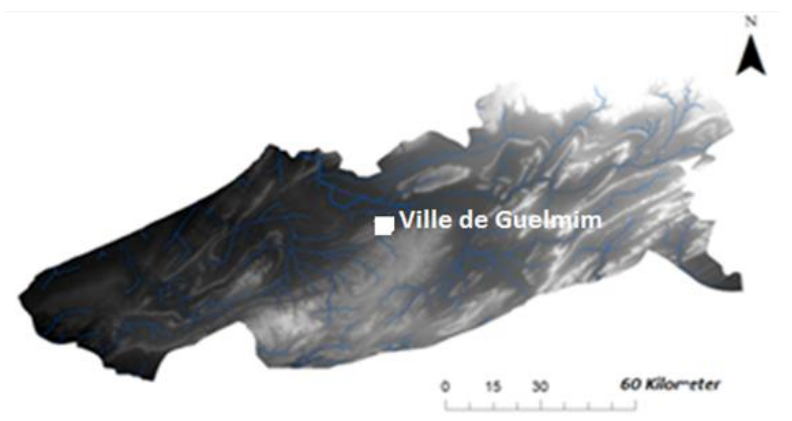

Fig. 2. Hydrographic Network of the Province of Guelmim.

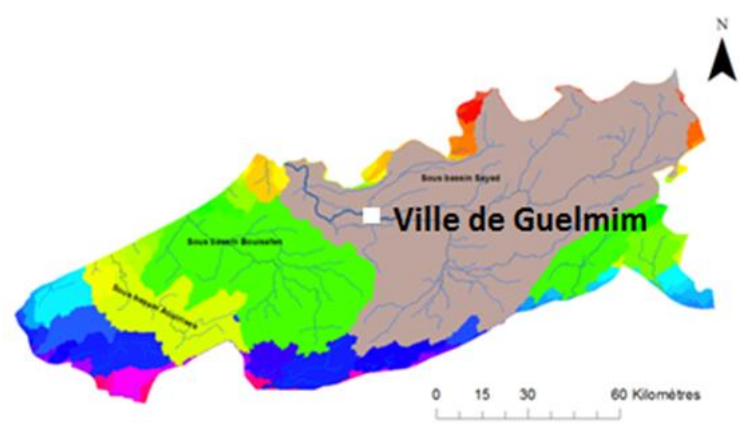

Fig. 3. Delimitation of the three main Guelmim sub-basins: Seyyad Basin, Bouissafen and Aourioura; and the hydraugraphic network via the MNT map.

The hydrological unit of Guelmim belongs to the geological domain of the anti-Atlas.

We encounter the phenomenon of water erosion, linked to the dynamics of water in different facies. The wind erosion is also encountered. We encounter also the phenomenon of desertification which is one of the problems that slow down the development of the region. The sanding phenomenon can also be caused by wind erosion, i.e. due to high winds combined with periods of severe drought.

\subsection{Flood events in the study area}

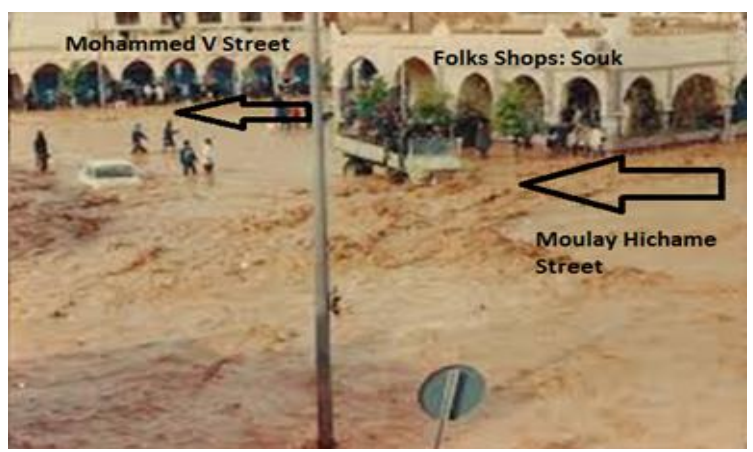

Fig. 4. Inundation in the city of Guelmim 1985.

During the month of January 1985; heavy rains recorded in the city (Watershed) leaded to an overflow of Oued Oum Laachar which caused flooding which had caused material and human damage.

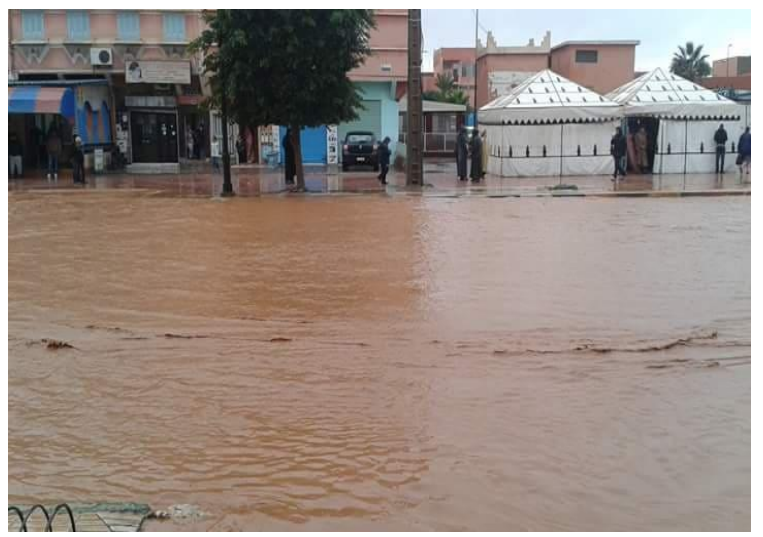


Fig. 5. Mohamed VI street (Main street in Guelmim) submerged in muddy water in November 2014.

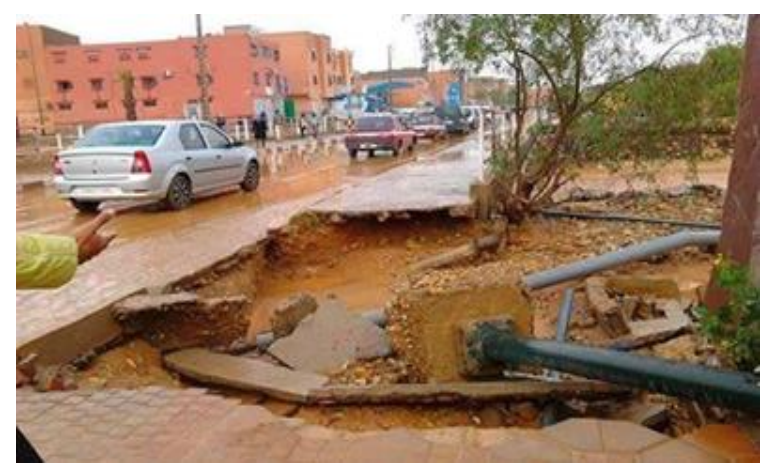

Fig. 6. The sidewalk dug by the overflow of Oued Oum Laachar in November 2014.

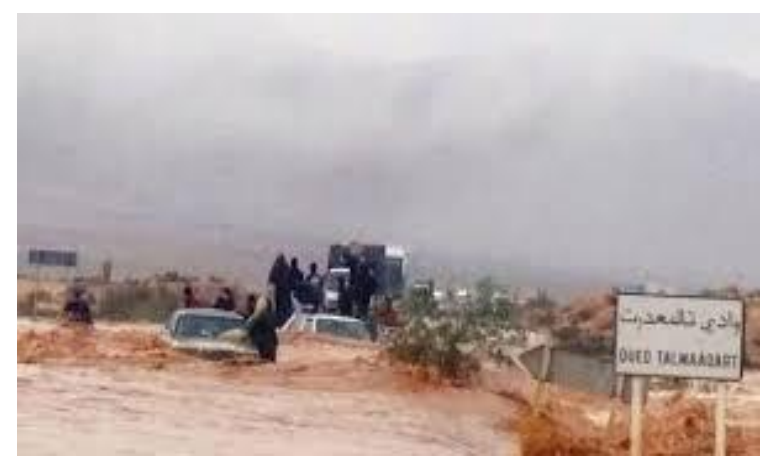

Fig. 7. Overflow of Oued TALMAADERT (Oued Oum Laachar effluent) causing damage in November 2014:the road is built on the minor and major river.

During the rains from 28 to 30 November 2014 torrential rains with very high intensity that exceeded $200 \mathrm{~mm}$ during twelve hours were recorded in the Lakhssass plateau and the Button of Sidi Ifni which constitute the watershed of the city of Guelmim, which has generated exceptional floods in rivers including the Oued Oum Laachar which is fed by a dozen streams from the AntiAtlas.

The flood of Oued Oum Laachar in November 2014 is estimated to be exceptional (at least in the last 40 years) which caused human damage 28 deaths washed away by the floods of Oueds Timsourt and Talmaadert tributary of the Oued Oum Laachar.

In Guelmim rural exodus and population growth have led to a dynamic of urbanization which has led to a change in land occupation, and causes risky events, uncontrolled and unplanned growth, thus contributes to the outbreaks of floods, since the developed massifs makes the passages more narrow, as well as it decreases the capacity of the catchment area. This change in land use with weather and hydrological events contributed to the floods.

\begin{tabular}{|c|c|c|c|}
\hline Use land & $\begin{array}{c}1990 \\
\left(\mathrm{Km}^{2}\right)\end{array}$ & $\begin{array}{c}2000 \\
\left(\mathrm{Km}^{2}\right)\end{array}$ & $\begin{array}{c}2014 \\
\left(\mathrm{Km}^{2}\right)\end{array}$ \\
\hline Open land & 5.5 & 4.5 & 4 \\
\hline Infrastructure & 3 & 4.5 & 5.5 \\
\hline Barren land & 6.5 & 6 & 5.5 \\
\hline
\end{tabular}

Table 1.Comparative table of land use in the city of Guelmim 1990, 2000 and 2014.

\section{Data and Methods}

\subsection{Dataset}

Observations data of precipitation used in this study are derived from Global Historical Climatological Network (GHCN) [5] for the period from 1985 to 2017. For the analysis of precipitation variability, standardized precipitation index is studied rather than precipitation sums to overcome problems of statistical analysis arising from the strong spatial heterogeneity of rainfall sums. The station used have minimum availability of missing data. This data set has been extensively quality controlled.

\subsection{Standardized Precipitation Index (SPI)}

In general, droughts characterization can be done based on their duration, severity and spatiotemporal variability [6], drought can be characterized in multiple ways $[7,8]$.

Drought indices are primary tools for defining different drought parameters, which include intensity, duration, severity and spatial extent. Several drought indices are developed in recent decades to quantify the drought for different time scales [9]. The Standardized Precipitation Index (SPI) $[10,11]$ is employed due to its advantages over other drought indexes, which includes:

- It is derived using rainfall records alone, so drought quantification is possible even if other hydrometeorological measurements are not available,

-Due to its flexibility over various timescales, it is possible to describe a range of meteorological, hydrological and agricultural applications,

- Due to its standardization, SPI ensures that drought quantification at any location and on any time scale are consistent.

The universal meteorological drought index,

Standardized Precipitation Index (SPI), is recommended by the WMO and developed by McKee and all[10], is less complicated and used to quantify the precipitation deficit for multiple time scales, reflecting the impact of precipitation deficiency on the availability of various water supplies.

A criteria defined for classifying droughts based on SPI values as shown in Table $2[10,12]$.

The SPI is defined by:

$S P I_{i}=\frac{X i-\bar{X}}{S d}$ 
$\mathrm{SPI}_{\mathrm{i}}$ is the standardized precipitation index in the cumulative period $i$,

$\boldsymbol{X}_{\mathrm{i}}$ is the cumulative precipitation for period i,

$\bar{X}$ is the average precipitation in cumulative period for historical series.

$\mathrm{Sd}$ is the standard deviation from average precipitation in the cumulative period $i$.

The classification shown in the table is used to define the intensities of the drought resulting from the calculation of the SPI.

\begin{tabular}{|c|c|}
\hline Category & SPI Index Interval \\
\hline Extremely wet & 2 and up \\
\hline Very wet & 1.60 to 1.99 \\
\hline Average wet & 1.30 to 1.59 \\
\hline Moderately wet & 0.80 to 1.29 \\
\hline Anormalement wet & 0.51 to 0.79 \\
\hline Close to normal & -0.50 to 0.50 \\
\hline Anormaly dry & -0.51 to -0.79 \\
\hline Moderately dry & -0.80 to -1.29 \\
\hline Average dry & -1.30 to -1.59 \\
\hline Very dry & -1.60 to -1.99 \\
\hline Extremely dry & -2.0 and under \\
\hline
\end{tabular}

Table 2. SPI drought severity classes for the wet and dry period according to the CDCC Centre's classification.

The choice of the SPI Index is related to its advantages in terms of statistical coherence and the ability to describe and quantify the precipitation at multiple time scales, it also analyzes wet periods as well as dry periods which leads to the possibility of ensuring an early alert of drought and analyzing wet periods as well as periods Dry.

\section{Results and discussion}

\subsection{Statistical study of the past and future variations of precipitation at the Guelmim station}

\subsubsection{Analysis of observed SPI index for the Guelmim station (1985-2017):}
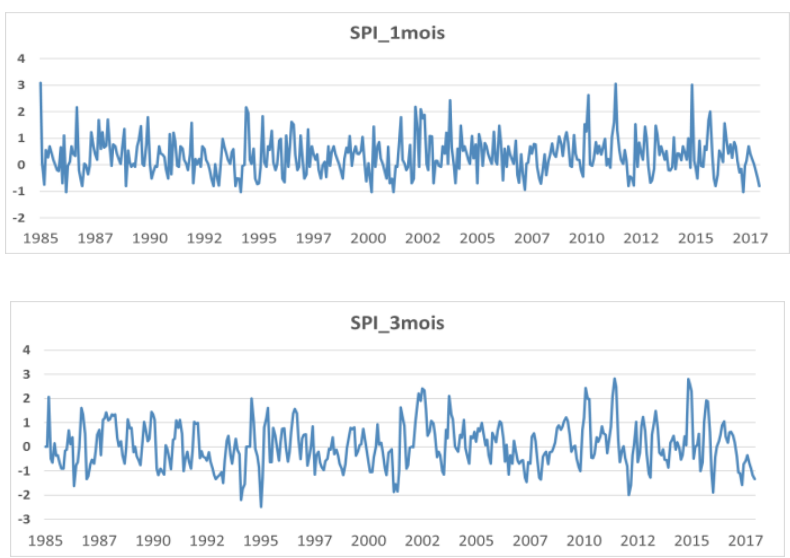
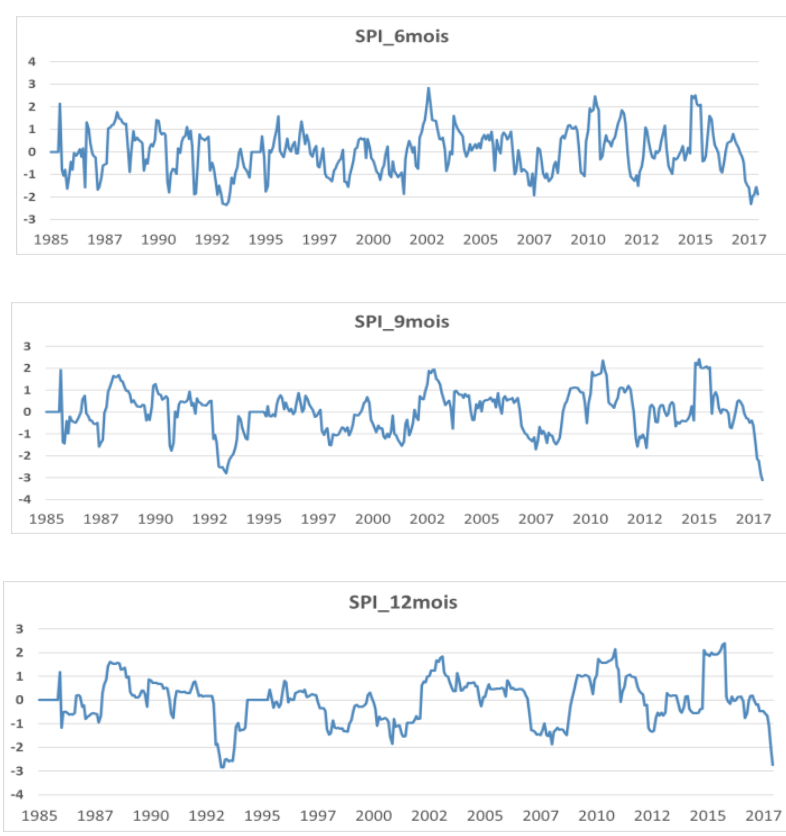

Fig. 8. SPI time series for Guelmim at 1, 3, 6, 9, 12 months' time step for the period 1985-2017.

In this study, the characteristics of precipitation variability in the Guelmim region are determined in by the use of the SPI. Monthly precipitation is used over 33 years (1985-2017). The temporal variability of precipitation is studied mainly by SPI applied to the different time series $(1,3,6,9$ and 12 months).

The monthly SPI_1mois (Figure 8) reflects short-term conditions; it is the meteorological drought; the years were the flooding occur in the region (1985 and 2014) has a maximum of SPI (3.0). For the rest of the years the SPI is located between -1 and 1 .We note that the variation of drought for SPI 1month is uniform during the 40 years of the study, and has a period of one to two years during the period 1985-2008 and of two to three years during the period 2008-2017.

The quarterly SPI (Figure 8) reflects the weather drought and we have a quarter period where the value of the SPI exceeds 2 (extremely wet). Similarly, we have dries periods where the value of the SPI is less than -1.5 . We note that the variation in drought for a period of three months have a periodicity of 8 to nine years, and reaches the maximum at 2010 (SPI $=-2.44)$.

The variation in wet quarters have ten-year periodicity and reaches the maximum (SPI=-2.5). The semi-annual SPI (Figure 8) show three peaks in wet periods, namely :2002; 2010 and 2014 which is the year of flooding in the region. We note a severe drought during the years of 1993,2000, 2006 and 2016 expressed by an SPI indicator value of less than 2 .

For the nine-month SPI(Figure 8), we note extremely wet in tree years with a maximum of SPI of -3.02 in 
November 2014 (Flood Month) and a drought during the year $1992(\mathrm{SPI}=-2.9)$.

The annual SPI (Figure 8) show only one year of extreme hydrological drought (1992) with an SPI of -2.8 , and maximum in wet in 2014.

\begin{tabular}{|c|c|c|c|c|c|}
\hline & $\begin{array}{c}1 \\
\text { month }\end{array}$ & $\begin{array}{c}3 \\
\text { months }\end{array}$ & $\begin{array}{c}6 \\
\text { months }\end{array}$ & $\begin{array}{c}9 \\
\text { months }\end{array}$ & $\begin{array}{c}12 \\
\text { months }\end{array}$ \\
\hline $\begin{array}{c}\text { Number } \\
\text { of cases } \\
\text { with } \\
\text { SPI }<0\end{array}$ & 137 & 294 & 189 & 254 & 168 \\
\hline $\begin{array}{c}\text { The } \\
\text { longest } \\
\text { duration } \\
\text { of } \\
\text { drought }\end{array}$ & 5 & 15 & 17 & 24 & 27 \\
\hline $\begin{array}{c}\text { Period } \\
\text { of } \\
\text { longest } \\
\text { duration }\end{array}$ & $\begin{array}{c}1993- \\
1994\end{array}$ & $\begin{array}{c}1992- \\
1993\end{array}$ & $\begin{array}{c}1992- \\
1993\end{array}$ & $\begin{array}{l}1999- \\
2000\end{array}$ & $\begin{array}{c}1997- \\
1999\end{array}$ \\
\hline $\begin{array}{c}\text { Number } \\
\text { of cases } \\
\text { with } \\
\text { SPI }>0\end{array}$ & 259 & 97 & 196 & 134 & 205 \\
\hline $\begin{array}{c}\text { The } \\
\text { longest } \\
\text { duration } \\
\text { of Wet }\end{array}$ & 12 & 12 & 24 & 27 & 32 \\
\hline $\begin{array}{c}\text { Period } \\
\text { of the } \\
\text { longest } \\
\text { duration }\end{array}$ & $\begin{array}{l}2008- \\
2009\end{array}$ & $\begin{array}{c}2002- \\
2003\end{array}$ & $\begin{array}{c}2002- \\
2003\end{array}$ & $\begin{array}{c}2002- \\
2004\end{array}$ & $\begin{array}{l}2002- \\
2004\end{array}$ \\
\hline
\end{tabular}

Table 3. Statistics derived from the SPI time series in the different scale at Guelmim.

\subsubsection{SPI Index correlations with NAO mode (North Atlantic Oscillation) for Guelmim station (1985-} 2016):

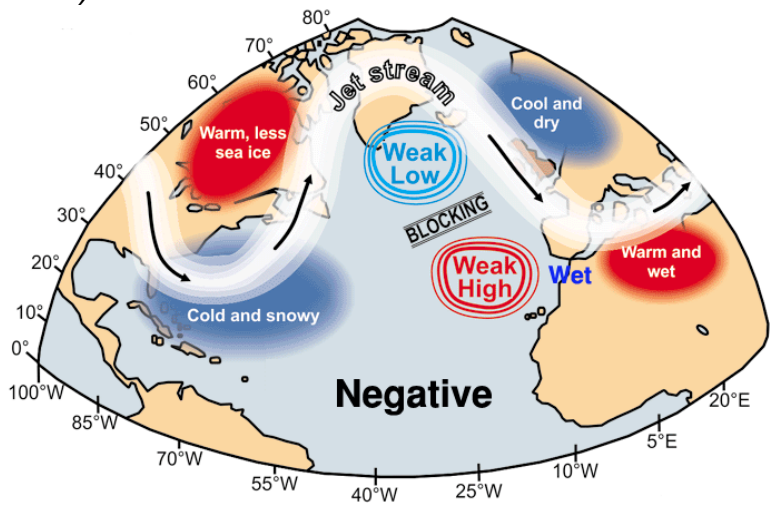

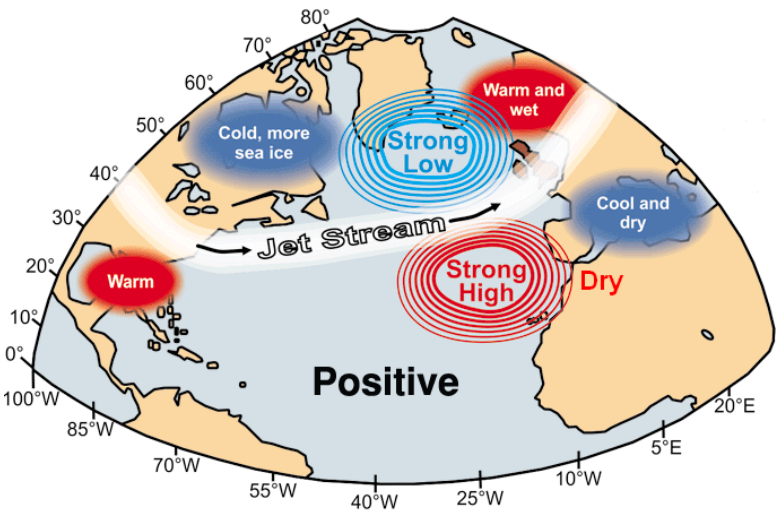

Fig. 9. Positive and negative phases of NAO and related weather conditions[13].

The North Atlantic Oscillation (NAO) is a climate phenomenon that has a very important role in the weather and oceanographic conditions of the North Atlantic. In this region, climate fluctuations at mid- and high latitudes are characterized by a small number of well-defined structures, showing strong large-scale spatial coherence over the Atlantic basin. The North Atlantic Oscillation is the dominant atmospheric mode especially in winter, its influence extending from the east coast of the United States to Eurasia and North Africa, to the Arctic [14]. The various previous studies have shown the influence of tropical and extratropical circulation patterns on the interannual variability of Moroccan and North African precipitation. Winter precipitation in Morocco are associated generally with the phenomena of North Atlantic Oscillation (NAO) which is a fluctuation in the difference of atmospheric pressure at sea level (SLP) between the Icelandic Low and the Azores High over the North Atlantic Ocean region(Figure 9) . In particular, the North Atlantic Oscillation (ONA) exerts some influence on Moroccan winter precipitation(Figure 9), which is negatively correlated to it, notably the western part of the Atlas Mountains [15].

In order to quantify the relationship between precipitation at Guelmim and NAO variability, a calculation of linear correlation coefficients between the SPI series (for the Guelmim station) and the NAO index over the period available (1985-2017) for different seasons and year has been established. The results of these correlations are illustrated in Figure 10 and 11:

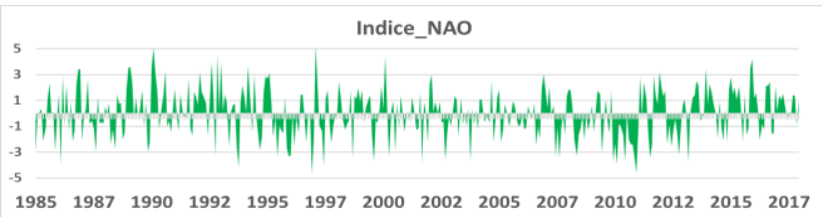

Fig. 10. The NAO index (1985-2017) (source: NOAA)

This curve in Figure 10 shows a fluctuation of NAO between the positive and the negative with $\mathrm{NAO}^{+1} \mathrm{~s}$ dominance. 


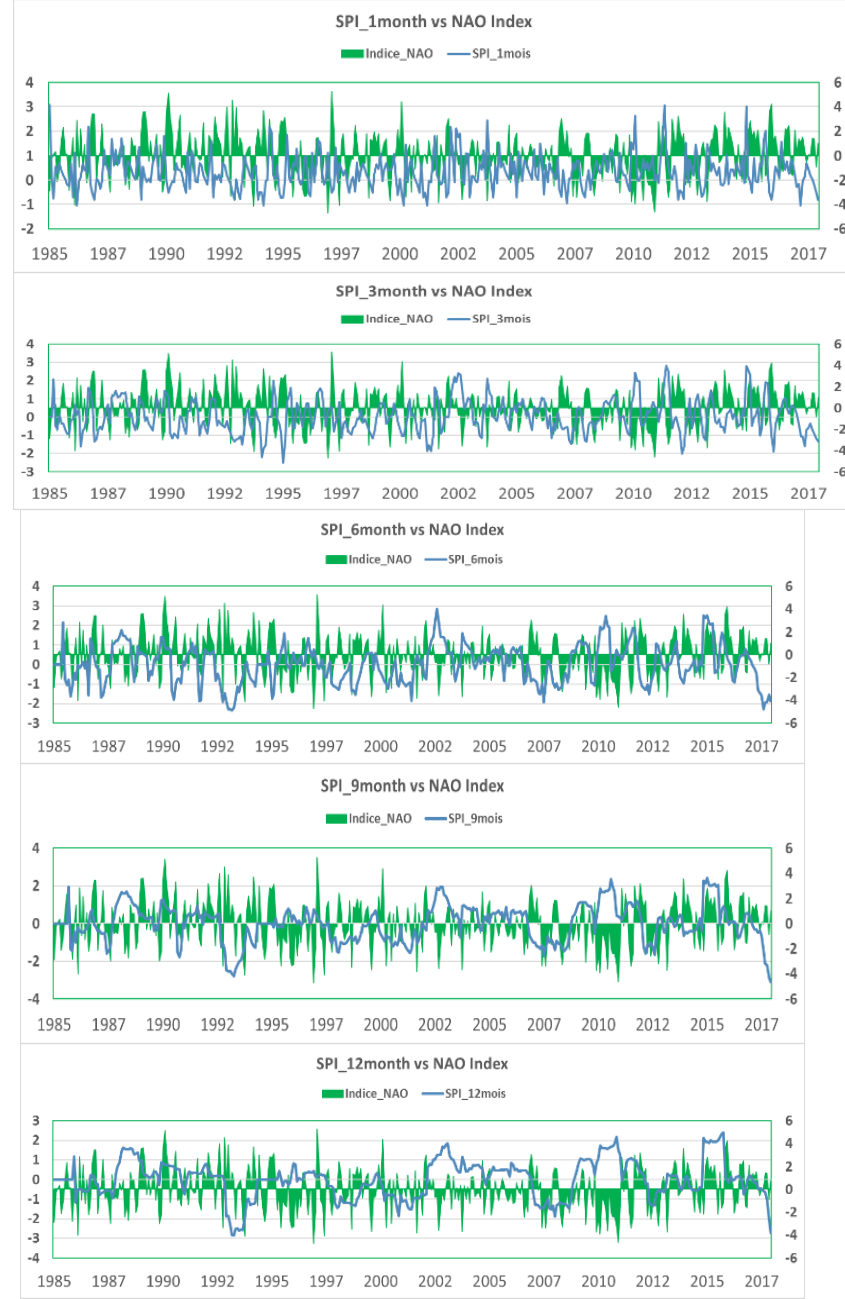

Fig. 11. Evolution of the NAO index with the Guelmim Precipitation SPI Index for different periods during the period 1985-2017

Monthly trends in the SPI for Guelmim (Figure 11) during the period 1985-2017 showed that we have 5 dries months which correspond to $80 \%$ in the NAO, this explain the rainfall deficits during these periods.

SPI_3month (Figure 11) showed 17 dries months, which correspond to $69.5 \%$ in the positive phase of NAO, this explain the rainfall deficits during these periods. The semi-annual SPI during the period 1985-2017 (Figure 11) showed 15 dries months that correspond to $75 \%$ of the positive phase of NAO. The nine-month trends in the SPI index in Guelmim during the period 1985-2017 showed that we have 12 dries months that correspond to $50 \%$ of the positive phase of NAO which helps to explain the much of the rainfall deficits during these periods.

The annual SPI index in Guelmim during the period 1985-2017 (Figure 11) showed that we have 10 hydrologically dries months in this station, which correspond to $46 \%$ of the positive NAO phase, that helps explain much of the rainfall deficits.
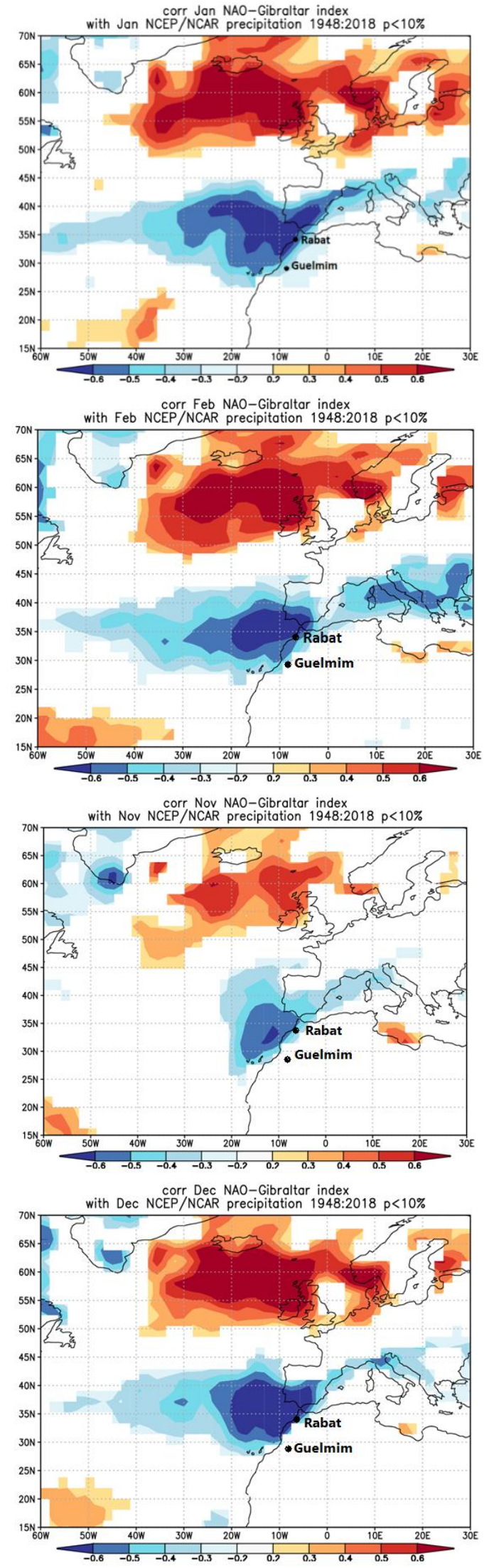


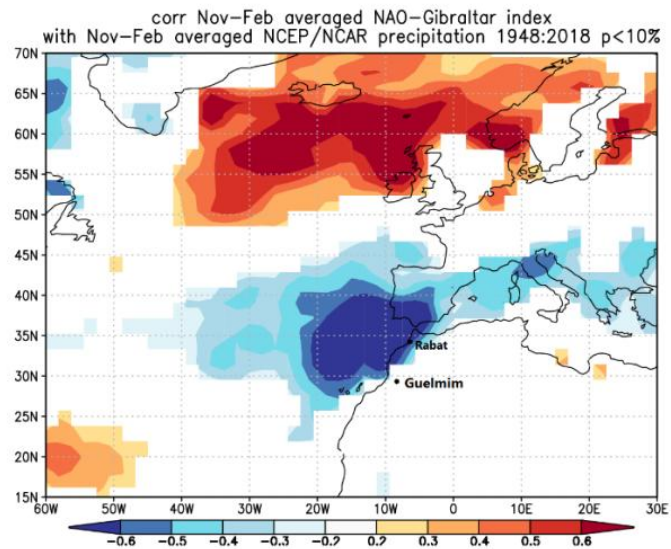

Fig. 12. Correlation maps between precipitation and the North Atlantic Oscillation Index (NAO) for the winter season during the period 19482018(NCEP/NCAR).

\subsubsection{Analysis of future trends in the SPI index for the Guelmim station (2020-2099):}

SPI_1mois (2020-2099)

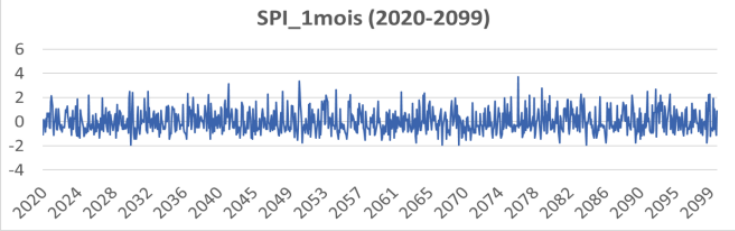

SPI_3mois (2020-2099)

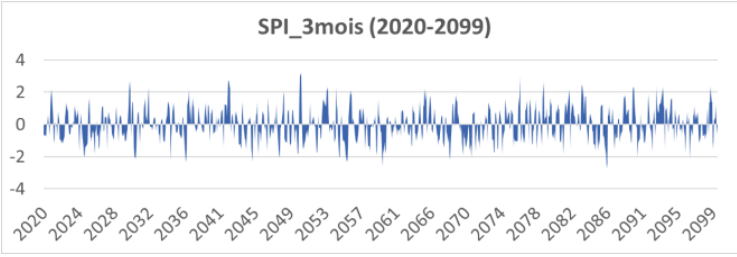

SPI_6mois (2020-2099)

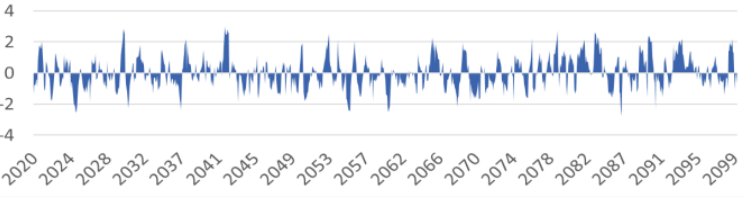

SPI_9mois (2020-2099)

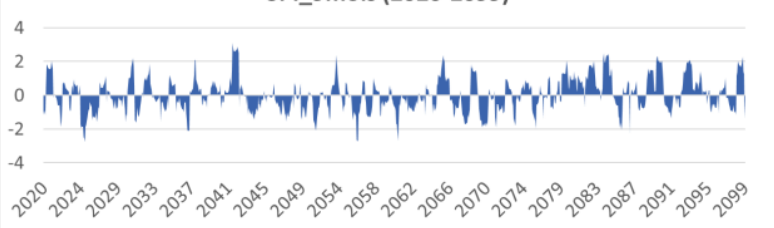

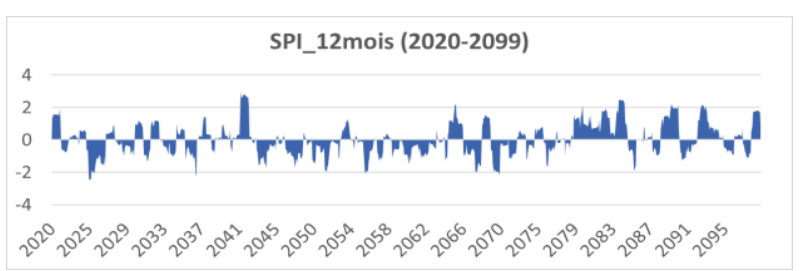

Fig. 13. SPI time series for Guelmim at time steps of 1, 3, 6, 9, 12 months for the period 2020-2099.

Generally, the times series of SPI for different time scales shows an alternation of dry and wet periods for the region of Guelmim during the period from 2020 to 2099.

For the future SPI (1 month 2020- 2099: Figure 13), we note six peaks of wet periods with a maximum in the year 2076 and 9 peaks of dry periods.

For the future SPI (3 months 2020- 2099: Figure 13), we note 22 peaks of wet periods with a maximum to the year 2050 and 37 peaks of drought with a maximum in the year 2086 .

For the future SPI (6 months 2020- 2099: Figure 13), we note 8 peaks in wet with a maximum in the year 2042 and 8 peaks of drought with a maximum in the year 2086.

For the future SPI (9 months 2020- 2099: Figure 13), we note 15 peaks of wet with a maximum in the year 2042; and 14 peaks of drought with a maximum in the year 2056.

For the future SPI (12 months 2020- 2099: Figure 13), we note 12 peaks of humidity with a maximum in the year 2042 and 13 peaks of drought with a maximum in the year 2025 .

\begin{tabular}{|c|c|c|c|c|c|}
\hline $\begin{array}{l}\text { Scale } \\
\text { (months) }\end{array}$ & 1 & 3 & 6 & 9 & 12 \\
\hline $\begin{array}{l}\text { Number of cases } \\
\text { with } \mathrm{SPI}<0\end{array}$ & 540 & 491 & 498 & 505 & 511 \\
\hline $\begin{array}{l}\text { The longest duration } \\
\text { of drought }\end{array}$ & 19 & 17 & 17 & 39 & 59 \\
\hline $\begin{array}{l}\text { Period of longest } \\
\text { duration }\end{array}$ & 2025 & $\begin{array}{l}2067 \\
/ 2068 \\
\end{array}$ & 2061 & \begin{tabular}{|l|}
2043 \\
$/ 2046$ \\
\end{tabular} & $\begin{array}{l}2058 \\
/ 2063\end{array}$ \\
\hline $\begin{array}{l}\text { Number of cases } \\
\text { with SPI>0 }\end{array}$ & 419 & 467 & 457 & 447 & 949 \\
\hline $\begin{array}{l}\text { The longest duration } \\
\text { of Wet }\end{array}$ & 15 & 14 & 33 & 31 & 76 \\
\hline $\begin{array}{l}\text { Period of the longest } \\
\text { duration }\end{array}$ & $\begin{array}{l}2049 \\
/ 2050\end{array}$ & 2050 & $\begin{array}{l}2092 \\
/ 2095 \\
\end{array}$ & \begin{tabular}{|l|}
2079 \\
$/ 2084$ \\
\end{tabular} & $\begin{array}{l}2078 \\
/ 2085 \\
\end{array}$ \\
\hline
\end{tabular}

Table 4. Statistics derived from the SPI time series in different scales in Guelmim

\section{Conclusion}

In this study, we have analyzed the variability of precipitation in Guelmim's region, which shows a strong irregular aspect with an overall trend of decreasing. The 
climate in Guelmim between 1985 entre 2017 showed a significant change in the annual and seasonal distribution. In this work, we have shown the link between North Atlantic Oscillation and precipitation in Guelmim. We can notice that the highly quantities of precipitations recorded during winter are associated with the negative phase of NAO.

The standardized precipitation index remains a very interesting tool for characterizing wet and dry periods. Through the analysis of this SPI index, we have detected a trend of increasing droughts in the future, we have also defined the driest periods in the recent as well as in the future. The Future SPI identifies a multitude and long periods of extreme droughts between the years 2020 and 2099.

\section{ACKNOWLEDGEMENTS}

we acknowledge the financial support of this article by the CNRST (National Centre for Scientific and technic research) located in Rabat .

\section{References}

1. Greefacts, Facts on Climate Change A summary of the 2007 Assessment. Report of the IPCC. 6 (2007)

2. Ben Sari,Prévision et prévention des catastrophes naturelles et environnementales- Le cas du Maroc.. Sciences de la Terre,Edition UNISCO.234 (2004)

3. Zurich and Targa Aide, Risk Nexus. Morocco floods of 2014: what we can learn from Guelmim and Sidi Ifni.Luigi T. De Luca, Propulsion physics (EDP Sciences, Les Ulis, 2009) Corporate Publishing Zurich Insurance Group.30(2015)

4. N. ElMahmouhi, M. ElWartiti, S. AstiteWissem , S.Kemmouand and S.EL Bahi.The use of geographic information system for the extraction of physical characteristics of assaka watershed: subbasins of sayed and oumlaachar wadis (southern Morocco) International Journal of Innovation and Applied Studies 371(2016)

5. National Oceanic and Atmospheric Administration (noaa) Global Historical Climatology Network (GHCN) ,Available in ligne: https://www.ncdc.noaa.gov/dataaccess/land-based-station-data/land-baseddatasets/global-historical-climatologynetwork-ghcn

6. X.Xue, Y. Hong, A.S. Limaye, J.J. Gourley ,G.J. Huffman, S.I. Khan, C. Dorji and S. Chen. Statistical and hydrological evaluation of TRMMbased multi-satellite precipitation analysis over the
Wangchu Basin of Bhutan: are the latest satellite precipitation products $3 \mathrm{~B} 42 \mathrm{~V} 7$ ready for use in ungauged basins J. Hydrol. 499 91-99 (2013)

7. J.Heim. A review of twentieth-century drought indices used in the United States. Bull. Am. Meteorol. Soc. 83 (8), 1149-1165 (2002)

8. J.Keyantash, J.A.Dracup, The quantification of drought: an evaluation of drought indices. Bull. Am. Meteorol. Soc. 83 (8), 1167-1180(2002)

9. A.K.Mishra, V.P.Singh.A review of drought concepts.J. Hydrol.391(1-2), 202- 216.391 (2010)

10. T.B. McKee, N.J. Doesken and J. Kleist. The relationship of drought frequency and duration to time scales. In: Proceedings of the 8th Conference on Applied Climatology. 17-22 January 1993, Anaheim, California. American Meteorological Society. (1993)

11. N.B. Guttman. Accepting the standardized precipitation index: a calculation algorithm. J. Am. Water Resour. Assoc. 35 (2), 311-322.Hargreaves, G.H., Samani, Z.A., 1985.

12. A.Dai .Drought under global warming: a review. Wiley Interdiscipl. Rev. Clim. Change 2 (1), 4565(2011)

13. M.Elkharrim.Statistical and dynamical study of temperature variability over northwestern region. Mohammed V University- Agdal (2014)

14. M. Visbeck,C.Ruth,P.Eric, D.Tom and K.Gerd. The Ocean's Response to North Atlantic Oscillation Variability 6.8 summary and discussion2 (2001)

15. f. Driouech.Distribution of winter precipitation over Morocco as part of climate change: descent of scale and uncertainties, doctoral thesis, universe, environmental and space sciences(sdu2e), Toulouse universuty164 (2010) 